\title{
Continuous Metabolic Syndrome Score in Children: How Useful is it?
}

\author{
Rajni Sharma ${ }^{1}$
}

Received: 22 July 2019 / Accepted: 23 July 2019 /Published online: 3 August 2019

(C) Dr. K C Chaudhuri Foundation 2019

India is facing a widespread epidemic of lifestyle illnesses including type 2 diabetes mellitus (T2DM) and cardiovascular disease (CVD), many of which have their antecedents in childhood and adolescence $[1,2]$. Reaven first described an association of T2DM and CVD morbidity and mortality in adults with a cluster of metabolic abnormalities, including central obesity, dyslipidemia, high fasting glucose and high blood pressure, which is now termed as 'Metabolic Syndrome' (MS) (formerly called syndrome ' $\mathrm{X}$ ') [3]. The underlying mechanism of MS has been postulated to be insulin resistance and hyperinsulinemia secondary to obesity [3]. With the rising prevalence of childhood obesity worldwide, MS is increasingly encountered in children. In India, MS affects $11-18 \%$ and $36-50 \%$ overweight and obese children, respectively, with an overall prevalence of $4-4.5 \%$ amongst urban adolescents $[4,5]$. In longitudinal studies, the adverse metabolic profile of childhood MS has been shown to persist into adulthood predisposing to adverse health outcomes [6].

Childhood MS is defined by the adult criteria of the National Education Program Adult Treatment Panel (ATPIII), modified for adolescents, which includes 3 out of 5 risk factors [waist circumference $>75^{\text {th }}$ percentile, high density lipoprotein (HDL) Cholesterol $<40 \mathrm{mg} / \mathrm{dl}$, fasting triglycerides $>/=100 \mathrm{mg} / \mathrm{dl}$, fasting blood sugar $>/=110 \mathrm{mg} / \mathrm{dl}$ and blood pressure $>90^{\text {th }}$ percentile) [7]. However, there are inherent fallacies in this binary definition of MS [8]. Many children with central obesity and hyperinsulinemia do not fulfill the criteria for MS due to ethnic or gender differences, though they are at high risk for T2DM and CVD [9]. The component risk factors of MS are not 'all or none'dichotomous variables but rather represent a continuous risk for adverse metabolic effects. Additionally, the definition does not reflect the

Rajni Sharma

drrajnisharma@yahoo.com

1 Division of Pediatric Endocrinology, Department of Pediatrics, All India Institute of Medical Sciences, New Delhi 110029, India severity of the metabolic derangements and how they evolve over time. In fact, the traditional definition of MS leads to loss of data and affects the statistical power of research studies, which may fail to show association with adverse outcomes even if they exist [10]. Hence, researchers have advocated the use of a continuous metabolic syndrome (cMetS) risk score to improve recognition of associations between risk and outcome in epidemiological studies [8]. Longitudinal studies have shown that the childhood cMetS risk score had a high correlation with adult onset T2DM and CVD [11]. The cMetS score has been shown to predict CVD risk in young adulthood more reliably [12] or equally well [11] compared to the traditional MS definition.

In this issue of the journal, Sawant and Amin examine the usefulness of cMetS risk score in predicting MS in a cohort of obese and overweight Indian children [13]. The authors used the residual $\mathrm{z}$-score method described by Eisenmann, by calculating the sum of the z-scores of each MS component of individual patients to yield the cMetS risk score [10]. The cMetS risk score correlated with the number of risk factors and predicted the presence of MS with great accuracy at the cut-offs suggested. However, the authors have derived cMetS score from the MS component $\mathrm{z}$-score of their cohort of patients and hence, the risk score and cut-offs may not be applicable to other populations. One way to overcome this limitation would be to use ethnic nationally representative (rather than sample specific) data for z-scores of MS risk components [14]. Secondly, the cMetS risk score calculation is based on the assumption that all components of MS contribute equally to disease risk; however, it is known that MS components may influence risk differentially depending on gender and ethnicity [15]. Some authors have tried to account for this by using confirmatory 'factor analysis' in calculating the cMetS score [15].

Further research is required to determine the usefulness of the cMetS risk score in predicting adverse health outcomes in the Indian population. Also, the clinical utility of the score to identify at-risk individuals and guide targeted lifestyle and 
pharmacological interventions needs to be explored. The cMetS risk score can be used to monitor trends in metabolic and CVD risk in the population [16] and also guide policymakers regarding efficacy of public health programmes. In conclusion, cMetS risk score is a valuable tool in the hands of researchers, clinicians and policy makers in addressing the childhood obesity and MS epidemic. Future research should identify Indian cut-off values and focus on monitoring trends and effectiveness of lifestyle interventions.

\section{Compliance with Ethical Standards}

\section{Conflict of Interest None.}

\section{References}

1. Pradeepa R, Mohan V. Prevalence of type 2 diabetes and its complications in India and economic costs to the nation. Eur J Clin Nutr. 2017;71:816-24.

2. Gupta R, Mohan I, Narula J. Trends in coronary heart disease epidemiology in India. Ann Glob Health. 2016;82:307-15.

3. Reaven GM. Role of insulin resistance in human disease. Diabetes. 1988;37:1595-607.

4. Tandon N, Garg MK, Singh Y, Marwaha RK. Prevalence of metabolic syndrome among urban Indian adolescents and its relation with insulin resistance (HOMA-IR). J Pediatr Endocrinol Metab. 2013;26:1123-30.

5. Singh R, Bhansali A, Sialy R, Aggarwal A. Prevalence of metabolic syndrome in adolescents from a north Indian population. Diabet Med. 2007;24:195-9.

6. Srinivasan SR, Myers L, Berenson GS. Predictability of childhood adiposity and insulin for developing insulin resistance syndrome (syndrome $\mathrm{X}$ ) in young adulthood: the Bogalusa heart study. Diabetes. 2002;51:204-9.

7. National Cholesterol Education Program (NCEP) Expert Panel on Detection, Evaluation, and Treatment of High Blood Cholesterol in
Adults (Adult Treatment Panel III). Third report of the National Cholesterol Education Program (NCEP) expert panel on detection, evaluation, and treatment of high blood cholesterol in adults (adult treatment panel III) final report. Circulation. 2002;106:3143-421.

8. Kahn R, Buse J, Ferrannini E, Stern M. The metabolic syndrome: time for a critical appraisal: joint statement from the American Diabetes Association and the European Association for the Study of diabetes. Diabetes Care. 2005;28:2289-304.

9. Sumner AE. Ethnic differences in triglyceride levels and highdensity lipoprotein lead to underdiagnosis of the metabolic syndrome in Black children and adults. J Pediatr. 2009;155:S7.e7-11.

10. Eisenmann JC. On the use of a continuous metabolic syndrome score in pediatric research. Cardiovasc Diabetol. 2008;7:17.

11. Magnussen CG, Cheriyan S, Sabin MA, et al. Continuous and dichotomous metabolic syndrome definitions in youth predict adult type 2 diabetes and carotid artery intima media thickness: the cardiovascular risk in Young Finns study. J Pediatr. 2016;171:97103.e1-3.

12. Kelly AS, Steinberger J, Jacobs DR, Hong CP, Moran A, Sinaiko AR. Predicting cardiovascular risk in young adulthood from the metabolic syndrome, its component risk factors, and a cluster score in childhood. Int J Pediatr Obes. 2011;6:e283-9.

13. Sawant SP, Amin AS. Use of continuous metabolic syndrome score in overweight and obese children. Indian J Pediatr. 2019. https://doi. org/10.1007/s12098-019-02994-5.

14. Guseman EH, Eisenmann JC, Laurson KR, Cook SR, Stratbucker W. Calculating a continuous metabolic syndrome score using nationally representative reference values. Acad Pediatr. 2018;18: 589-92.

15. Gurka MJ, Ice CL, Sun SS, Deboer MD. A confirmatory factor analysis of the metabolic syndrome in adolescents: an examination of sex and racial/ethnic differences. Cardiovasc Diabetol. 2012;11: 128.

16. Lee AM, Gurka MJ, DeBoer MD. Trends in metabolic syndrome severity and lifestyle factors among adolescents. Pediatrics. 2016;137:e20153177.

Publisher's Note Springer Nature remains neutral with regard to jurisdictional claims in published maps and institutional affiliations. 